\title{
Detection of Feline Coronavirus RNA in Feces, Tissues, and Body Fluids of Naturally Infected Cats by Reverse Transcriptase PCR
}

\author{
ARNOLD A. P. M. HERREWEGH, ${ }^{1 *}$ RAOUL J. DE GROOT, ${ }^{1}$ ARNOST CEPICA, ${ }^{2}$ \\ HERMAN F. EGBERINK, ${ }^{1}$ MARIAN C. HORZINEK, ${ }^{1}$ \\ AND PETER J. M. ROTTIER ${ }^{1}$ \\ Institute of Virology, Department of Infectious Diseases and Immunology, Veterinary Faculty, University Utrecht, \\ Yalelaan 1, 3584 CL Utrecht, The Netherlands, ${ }^{1}$ and Department of Pathology and Microbiology, \\ Atlantic Veterinary College, University of Prince Edward Island, Charlottetown, Canada ${ }^{2}$
}

Received 5 July 1994/Returned for modification 13 September 1994/Accepted 12 December 1994

\begin{abstract}
A nested reverse transcriptase PCR (RT-nPCR) was developed for the detection of feline coronavirus (FCoV) RNA in the feces, tissues, and body fluids of infected cats. The RT-nPCR was targeted to the highly conserved $3^{\prime}$-untranslated region of the viral genome and will detect most, if not all, feline coronaviruses in the field. With the RT-nPCR, FCoV RNA was detected in plasma samples from experimentally infected cats as early as 2 days postinoculation. FCoV RNA was also detected in serum, plasma, or ascitic fluid samples from 14 of 18 cats (78\%) with naturally occurring feline infectious peritonitis (FIP). The use of RT-PCR for FIP diagnosis is limited because of the occurrence of apparently healthy FCoV carriers. These asymptomatic cats shed the virus in the feces and, in a number of cases, also had detectable virus in the plasma. Because of the nature of FCoV infections, our RT-PCR assay with plasma or serum cannot be used to establish a definite diagnosis of FIP. However, this assay does provide a new means to identify asymptomatic FCoV carriers. As such, RT-nPCR will be of use to screen cats before their introduction into FCoV-free catteries. Moreover, this assay provides an important tool to study the epidemiology of $\mathrm{FCoV}$.
\end{abstract}

Feline infectious peritonitis (FIP) is a fatal, immune-mediated, pyogranulomatous disease of domestic and wild cats (for a review, see reference 31). The causative agent, FIP virus (FIPV), is a member of the family Coronaviridae, a group of enveloped, positive-stranded RNA viruses. Feline coronaviruses (FCoVs) differ widely in their pathogenic potentials (32, 36). Some isolates cause FIP in virtually $100 \%$ of experimentally infected cats, while others produce mild enteric infections. These avirulent isolates are commonly referred to as feline enteric coronaviruses (FECVs) (30). However, FECVs and FIPVs are serologically and genetically indistinguishable (7, 9, 13, 17-19, 33) and represent virulence variants of the same virus rather than separate virus species.

The key pathogenic event in FIP is the infection of monocytes and macrophages $(27,44)$. Avirulent FCoVs are thought to remain confined to the digestive tract and not to spread beyond the intestinal epithelium and regional lymph nodes (14, 35). FIPV, however, disseminates to other organs, most likely via blood-borne monocytes $(41,45)$.

FCoVs are found frequently in cats: antibodies are present in 80 to $90 \%$ of the cats in catteries and in 10 to $50 \%$ of those in single-cat households $(1,2,21,28,39,40)$. Because only 5 to $10 \%$ of seropositive cats die of FIP $(1,28,29)$, it is believed that most cats become infected with avirulent FCoV strains $(30,35)$. However, factors such as the susceptibility and age of the host, stress on the host, and virus dose clearly influence the outcome of an infection with virulent FCoV; a large proportion of healthy seropositive cats may in fact have experienced a sublethal infection with FIPV. There is circumstantial evidence for the occurrence of healthy, asymptomatic carriers (1, 32).

* Corresponding author. Phone: 0031-30-534195/532485. Fax: 0031$30-536723$
FIP is often misdiagnosed (30). Its general signs-chronic fever, weight loss, anorexia, and malaise-are nonspecific. In classical "wet" or "effusive" FIP, these signs are accompanied by a gradual abdominal distension with a viscous yellow ascitic fluid (31). Another form of FIP, in which little or no exudate is present, occurs. This so-called "dry" or "noneffusive" FIP is difficult to recognize (24). The ocular and neurologic problems frequently seen in cats with noneffusive FIP are also observed with other conditions of bacterial and viral origin (39). The clinicopathological changes in FIP (lymphopenia, neutrophilia, anemia, hyperproteinemia, and hypergammaglobulinemia) are nonspecific and not helpful in making a differential diagnosis (39). Serology is extensively used as a diagnostic tool: rising or high titers $(\geq 400)$, as measured by immunofluorescence, are assumed to be indicative of FIP $(3,21,28)$. However, in view of the facts that a large percentage of the healthy cat population is FCoV seropositive and that high antibody titers are frequently found in asymptomatic cats, the data from coronavirus serology must be interpreted with care $(1,2,38-40)$. At present, a definite diagnosis of FIP can be established only by histopathologic examination of biopsy or postmortem material $(39,40)$.

Compared with serology, reverse transcriptase PCR (RTPCR) provides the obvious advantage of directly detecting an ongoing infection rather than documenting a previous immune system encounter with a coronavirus. The aim of this study was to explore the use of RT-PCR in FIP diagnosis. We describe a nested RT-PCR (RT-nPCR) assay for the detection of FCoV RNA in tissues, body fluids, and feces of infected cats. Although in most cats with FIP, FCoV RNA was readily detected in the blood, the use of RT-nPCR for FIP diagnosis is limited because of the occurrence of apparently healthy FCoV carriers. Our RT-nPCR assay does provide, however, a new means to identify asymptomatic FCoV carriers. 
TABLE 1. FCoV reference strains

\begin{tabular}{|c|c|c|c|c|}
\hline Strain & $\begin{array}{l}\text { Sero- } \\
\text { type }^{a}\end{array}$ & Source $^{b}$ & $\begin{array}{l}\text { Refer- } \\
\text { ence }\end{array}$ & Provider \\
\hline \multicolumn{5}{|l|}{ FIPV } \\
\hline $79-1146$ & II & Fcwf cells, TC & 23 & N. Pedersen \\
\hline TN406 (Black) & I & Fcwf cells, TC & 5 & N. Pedersen \\
\hline Dahlberg & & $\begin{array}{l}\text { Mouse brain homog- } \\
\text { enate }\end{array}$ & 26 & A. Osterhaus \\
\hline UCD1 & $\mathrm{I}^{c}$ & Fcwf cells, TC & 34 & N. Pedersen \\
\hline UCD3 & $\mathrm{I}^{c}$ & Fcwf cells, TC & 36 & N. Pedersen \\
\hline UCD4 & $\mathrm{I}^{c}$ & Fcwf cells, TC & 36 & N. Pedersen \\
\hline UCD5 & & Omentum & & N. Pedersen \\
\hline UCD6 & & Omentum & & N. Pedersen \\
\hline Wellcome & & FEL cells, TC & 25 & D. Harbour \\
\hline NOR15 & II & Fcwf cells, TC & 12 & J. Evermann \\
\hline \multicolumn{5}{|l|}{ FECV } \\
\hline UCD & I & Feline feces & 35 & N. Pedersen \\
\hline $79-1683$ & II & Fcwf cells, TC & 23 & J. Evermann \\
\hline
\end{tabular}

${ }^{a}$ Assignment according to Pedersen et al. (33).

${ }^{b} \mathrm{TC}$, tissue culture supernatant fraction.

${ }^{c}$ Tentatively assigned to serotype I $(8,18,19)$.

\section{MATERIALS AND METHODS}

Virus and clinical specimens. The FCoV reference strains and their sources are listed in Table 1. Strains 79-1146, NOR15, 79-1683, and TN406 were grown in fcwf-D (Felis catus whole fetus) cells as described previously (11). FIPV strains UCD1, UCD3, and UCD4 were obtained from the tissue culture supernatant fraction from infected fcwf-D cells. FIPV strains UCD5 and UCD6 were recovered from omental samples. FECV strain UCD was recovered from feces. All of these materials were generously provided by Niels Pedersen. The tissue culture supernatant fraction of FEL (feline embryonic lung) cells containing the Wellcome strain was kindly provided by David Harbour. Mouse brain homogenate containing FIPV strain Dahlberg was a gift from Albert Osterhaus. Tissue and ascitic fluid samples from cats with naturally occurring FIP were included in the survey. In these cats, a definite FIP diagnosis was established by postmortem histopathologic examination. Fecal and plasma samples from cats suspected of having natural $\mathrm{FCoV}$ infection were obtained from a cattery of Norwegian Forest cats. Plasma samples were also collected from cats experimentally infected with FIPV strain 79-1146. In addition, plasma, serum, and ascitic fluid samples were collected from 26 cats for which FIP was considered a presumptive diagnosis. These latter samples were kindly provided by Katrin Hartmann.

Sample preparation. Tissue culture supernatant fractions and mouse brain homogenate (26) containing reference virus (Table 1) were diluted 1:50 in phosphate-buffered saline (PBS) and used directly in the RT reaction. Omentum, kidney, liver, and spleen samples, stored at $-20^{\circ} \mathrm{C}$, were homogenized in an equal volume of PBS in an Eppendorf tube. Insoluble components were removed by centrifugation for $10 \mathrm{~min}$ at $10,000 \times g$. The fatty upper layer, if present, was discarded, and the supernatant fraction was collected, diluted 1:50 in PBS, and used directly in the RT reaction. Ascitic fluid was diluted 1:100 in PBS.

Fecal samples were suspended 1:1 (vol/vol) in PBS and homogenized by vigorous vortexing. Insoluble components were pelleted for $10 \mathrm{~min}$ at 10,000 $\times$ $g$, and the supernatant fraction was stored at $-20^{\circ} \mathrm{C}$. For analysis, the samples were thawed, diluted 1:100 in PBS, and used directly in the RT reaction.

Plasma of experimentally infected cats was collected from EDTA-blood and stored at $-20^{\circ} \mathrm{C}$. Viral RNA from $100 \mu \mathrm{l}$ of plasma or serum was concentrated by the guanidinium thiocyanate-silica $\left(\mathrm{SiO}_{2}\right)$ protocol of Boom et al. (6) but with 20 rather than $40 \mu \mathrm{l}$ of the $50 \% \mathrm{SiO}_{2}$ suspension. The RNA was eluted from the silica pellet with $25 \mu \mathrm{l}$ of TE (10 mM Tris-HCl [pH 8.0], $0.5 \mathrm{mM}$ EDTA) by a 10 -min incubation at room temperature followed by a 10 -min incubation at $65^{\circ} \mathrm{C}$. The silica was pelleted by centrifugation, and the supernatant fraction was used in the RT reaction.

Primer selection and RT reaction. The oligonucleotide primer sequences were chosen from the highly conserved $3^{\prime}$-untranslated region (3'-UTR) of the FCoV genome (Fig. 1; Table 2).

In the lid of a $1.5-\mathrm{ml}$ reaction tube, $8.5 \mu \mathrm{l}$ of RNA-containing sample was added to the first premix, consisting of $3 \mu$ l of $5 \times$ RT buffer $(250 \mathrm{mM}$ Tris- $\mathrm{HCl}$ [pH 8.3 at $\left.\left.22^{\circ} \mathrm{C}\right], 375 \mathrm{mM} \mathrm{KCl}\right), 2 \mu \mathrm{l}$ of primer P211 $[5 \mu \mathrm{M}]$, and $0.5 \mu \mathrm{l}$ of a freshly prepared diethyl pyrocarbonate (Fluka Chemi AG, Buchs, Germany) -ethanol mixture $(0.8 \%$ [vol/vol] diethyl pyrocarbonate in $96 \%$ ethanol). The lid was closed, and the template- premix solution was spun down. The tube was allowed to stand for at least $5 \mathrm{~min}$ at room temperature and was then incubated for $10 \mathrm{~min}$ at $100^{\circ} \mathrm{C}$. Subsequently, the tube was placed on ice, and $6 \mu \mathrm{l}$ of the second premix, containing $1 \mu \mathrm{l}$ of $5 \times \mathrm{RT}$ buffer, $2 \mu \mathrm{l}$ of dithiothreitol $(100 \mathrm{mM})$, $1 \mu \mathrm{l}$ of a mixture of the four $2^{\prime}$-deoxynucleoside $5^{\prime}$-triphosphates (10 $\mathrm{mM}$ each), $1 \mu \mathrm{l}$ of RNAguard/RNase inhibitor (30 to $40 \mathrm{U} / \mu \mathrm{l}$ ) (Pharmacia Biochemicals,

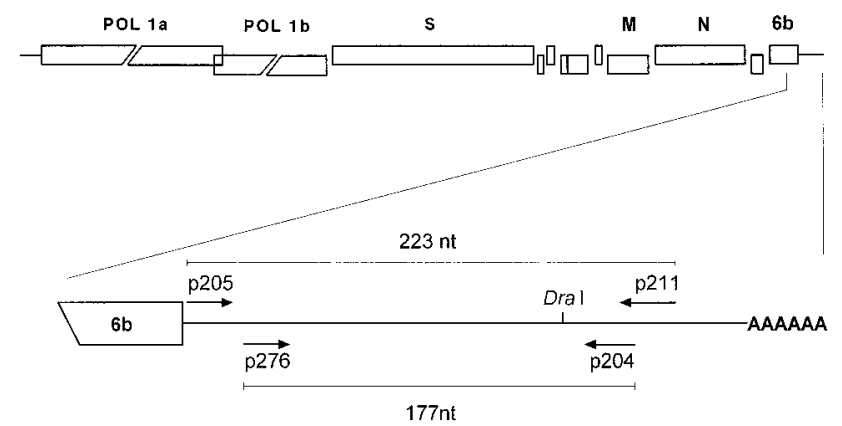

FIG. 1. Outline of the RT-nPCR. The upper part shows the genomic organization of the FCoV genome. The various FCoV genes are represented by boxes. The genes for the polymerase (POL 1a and POL 1b), the spike protein $(\mathrm{S})$, the membrane protein $(\mathrm{M})$, the nucleocapsid protein $(\mathrm{N})$, and the nonstructural protein $6 \mathrm{~b}$ are indicated. In the lower part the positions of the oligonucleotides in the $3^{\prime}$-UTR are shown. Arrows indicate the $5^{\prime}$-to-3' orientations. Also shown are the lengths of the products of the first and the nested PCRs. The DraI restriction site is located at position 170 as measured from the termination codon of open reading frame $6 \mathrm{~b}(10)$. nt, nucleotides.

Milwaukee, Wis.), and $1 \mu \mathrm{l}$ of Moloney murine leukemia virus RT (200 U/ $\mu \mathrm{l})$ (Gibco BRL Life Technologies, Gaithersburg, Md.), was added. This reaction mixture was spun down and incubated at $37^{\circ} \mathrm{C}$ for $60 \mathrm{~min}$.

PCR amplification. The RT-PCR assay was optimized with cytoplasmic RNA isolated from fcwf cells infected with FIPV strains TN406 and 79-1146. The optimal $\mathrm{MgCl}_{2}$ concentrations for the first and second PCRs were established at 2 and $1.5 \mathrm{mM}$, respectively.

Following reverse transcription, $10 \mu \mathrm{l}$ of the $\mathrm{RT}$ reaction mixture was added to $90 \mu \mathrm{l}$ of the PCR mixture. The PCR mixture consisted of $10 \mathrm{mM}$ Tris- $\mathrm{HCl}(\mathrm{pH}$ 9.0 at $25^{\circ} \mathrm{C}$ ), $50 \mathrm{mM} \mathrm{KCl}, 0.1 \%$ Triton $\mathrm{X}-100,2 \mathrm{mM} \mathrm{MgCl}, 150 \mu \mathrm{M}$ each $2^{\prime}$-deoxynucleoside $5^{\prime}$-triphosphate, $200 \mathrm{nM}$ sense primer P205, $150 \mathrm{nM}$ antisense primer P211, and $2 \mathrm{U}$ of Taq DNA polymerase (Promega Corp., Madison, Wis.). The reaction mixture was overlaid with $100 \mu \mathrm{l}$ of light white mineral oil (Sigma, St. Louis, Mo.) and placed in a thermal cycler (Perkin-Elmer Cetus, Norwalk, Conn.). The temperature cycling protocol consisted of $5 \mathrm{~min}$ of preheating at $90^{\circ} \mathrm{C}$ followed by 40 cycles of $50 \mathrm{~s}$ of denaturation at $94^{\circ} \mathrm{C}, 1 \mathrm{~min}$ of primer annealing at $55^{\circ} \mathrm{C}$, and $1 \mathrm{~min}$ of primer extension at $72^{\circ} \mathrm{C}$.

Ten microliters of the first amplification reaction mixture was used for a second round of amplified with the nested pair of primers in a 100- $\mu$ l reaction volume containing $10 \mathrm{mM}$ Tris- $\mathrm{HCl}\left(\mathrm{pH} 9.0\right.$ at $\left.25^{\circ} \mathrm{C}\right), 50 \mathrm{mM} \mathrm{KCl}, 0.1 \%$ Triton $\mathrm{X}-100,1.5 \mathrm{mM} \mathrm{MgCl}_{2}, 200 \mu \mathrm{M}$ each 2'-deoxynucleoside 5'-triphosphate, $200 \mathrm{nM}$ sense primer P276, $200 \mathrm{nM}$ antisense primer P204, and $2 \mathrm{U}$ of Taq DNA polymerase. For the nested PCR, 35 cycles of $50 \mathrm{~s}$ of denaturation at $94^{\circ} \mathrm{C}, 1 \mathrm{~min}$ of primer annealing at $55^{\circ} \mathrm{C}$, and $1 \mathrm{~min}$ of primer extension at $72^{\circ} \mathrm{C}$ were employed.

Analysis of PCR-amplified products. A $15-\mu l$ sample from each PCR mixture was analyzed in a $2 \%$ agarose gel. HinfI-digested pGEX-1 (37) was used as a molecular weight marker. Amplification products were visualized by ethidium bromide staining. Samples revealing a band of $177 \mathrm{bp}$ after the nested PCR were considered positive for coronavirus RNA. The identities of the PCR products were confirmed by DraI digestion, which yielded products of 35 and $142 \mathrm{bp}$. This restriction enzyme reaction was performed directly with the $15-\mu$ l PCR sample. Nucleotide sequencing of PCR products was performed with a cycle sequencing kit (Gibco BRL Life Technologies) and one of the PCR primers. The PCR DNA was purified by electrophoresis in $1 \%$ SeaPlaque GTG low-melting-point agarose gel (FMC BioProducts, Rockland, Maine) run in $0.4 \times$ TAE $(1 \times$ TAE consists of $0.04 \mathrm{M}$ Tris-acetate and $0.001 \mathrm{M}$ EDTA). Cycle sequencing was performed directly on molten gel slices containing approximately $40 \mathrm{ng}$ of the PCR product.

Precautions taken to avoid carryover of amplification products included physical separation of the pre- and post-PCR procedures, the use of aerosol-resistant tips (BioZyme, Kerkrade, The Netherlands), manipulation in a flow cabinet, and

TABLE 2. Oligonucleotide primers used in the RT-nPCR assay

\begin{tabular}{|c|c|c|c|}
\hline Primer & Sequence $\left(5^{\prime}\right.$ to $\left.3^{\prime}\right)$ & Position $^{a}$ & Orientati \\
\hline 20 & $\mathrm{CC}$ & & \\
\hline $\mathrm{P} 20$ & $G G$ & & Sen \\
\hline P211 & GATCCAGA & 213-192 & Antisen \\
\hline P276 & CCGAGGAATTACTGGTCATCGCG & $29-51$ & Sense \\
\hline
\end{tabular}

${ }^{a}$ Numerical position on the genome of FIPV strain $79-1146$ as determined from the termination codon of open reading frame $6 \mathrm{~b}(10)$. 
preparation of master mix solutions to reduce manipulation of RT-PCR mixture components. In each run, at least two negative controls of distilled $\mathrm{H}_{2} \mathrm{O}$ were included alongside the test samples.

Anti-FCoV antibody titers. Anti-FCoV antibody titers were determined by immunofluorescence assay. Swine kidney cells were inoculated with porcine transmissible gastroenteritis virus (TGEV) at a multiplicity of infection of 10 $\mathrm{PFU} / \mathrm{cell}$ and incubated for $8 \mathrm{~h}$ at $37^{\circ} \mathrm{C}$. Subsequently, the cells were trypsinized, mixed with approximately $50 \%$ uninfected cells, and seeded onto eight-well glass plates (Nutacon, Amsterdam, The Netherlands). The cells were fixed in cold acetone and stored at $-20^{\circ} \mathrm{C}$. The glass plates were washed before use. Cells were incubated for $60 \mathrm{~min}$ at $37^{\circ} \mathrm{C}$ with serial twofold dilutions of plasma or serum samples in PBS. After the plates were washed three times for $5 \mathrm{~min}$ each time, fluorescein isothiocyanate-conjugated goat anti-feline immunoglobulin G was added to the wells. The plates were incubated for $60 \mathrm{~min}$ at $37^{\circ} \mathrm{C}$ and washed, and fluorescence was determined with an Olympus BHS-F microscope.

\section{RESULTS}

Design of a coronavirus-specific RT-nPCR assay. An assay for the detection of FCoV RNA in sera and feces of infected cats would provide a useful tool in establishing FIP diagnosis and a means to identify asymptomatic virus shedders. For this purpose, we developed an RT-nPCR assay specific for the $3^{\prime}$-UTR of the viral genome. A comparison of eight independent FCoV isolates revealed 97 to $100 \%$ nucleotide sequence identity in the $3^{\prime}$-UTR (17). The sequence of this region is also highly conserved in TGEV and in canine coronavirus (CCV) $(10,20,43)$.

The nucleotide sequences of the primers and their locations on the FCoV genome are presented in Table 2 and Fig. 1. The primers were derived from sequences that are conserved among TGEV, CCV, and the various FCoV isolates. Primer sets were chosen so as to yield short amplification products, i.e., 223 and $177 \mathrm{bp}$ for the first and second PCRs, respectively (Fig. 1), in order to facilitate complete extension even if the quality of the RNA template was poor. The resulting PCR products contain a DraI restriction site that is conserved in all FCoV strains analyzed thus far.

Specificity of primers. To determine whether the assay detects different FCoV strains, tissue culture supernatant fractions from eight FCoV strains (Table 1) were subjected to RT-nPCR. This collection contained FIPV strains tentatively assigned to serotypes I (TN406, UCD1, UCD3, and UCD4) and II (79-1146 and NOR15) $(8,18,19,33)$ and an FIPV strain not yet assigned to a group (Wellcome), as well as the type II FECV strain 79-1683 (33). In all cases, products of 223 and 177 bp were found after the first PCR and the nested PCR, respectively (Fig. 2). The identities of these products were confirmed by $\mathrm{DraI}$ digestion and nucleotide sequence analysis. Four additional FCoV strains that had been passaged only in vivo were studied by performing RT-nPCR directly with mouse brain homogenate (FIPV strain Dahlberg), tissue homogenates (FIPV strains UCD5 and UCD6), and feces (FECV strain UCD). Again, specific PCR products of 223 and $177 \mathrm{bp}$ were obtained (Fig. 2).

As a final control, samples from five cats that had died from natural FIP as determined by histopathological examination were studied. Tissue homogenates of omentum, kidney, spleen, and liver were subjected to the RT-nPCR. In all cases, the coronavirus-specific 177-bp PCR product was obtained after the nested PCR.

Detection of FCoV RNA in experimentally and naturally infected cats. To be of use as a diagnostic tool, the RT-nPCR assay should be sensitive enough to detect viral RNA in the plasma of infected cats. We therefore inoculated four cats oronasally with 1,000 PFU of FIPV strain 79-1146. Blood samples were taken three days before inoculation and at days 2,4 , $7,10,15,18$, and 22 postinoculation (p.i.). The cats were euthanized in extremis at 22 days p.i. An RT-nPCR performed
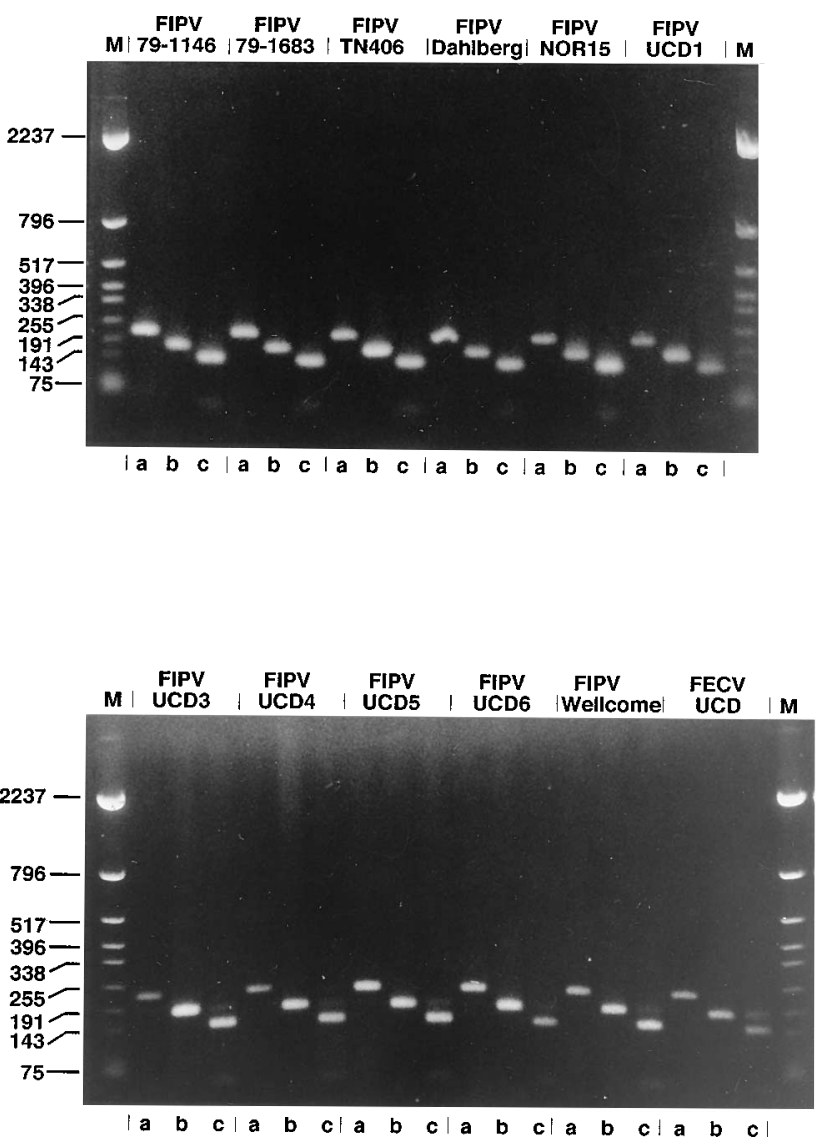

FIG. 2. RT-PCR performed with various FCoV isolates. Lanes a, 223-bp products of the first PCR with oligonucleotides P205 and P211; lanes b, 177-bp products of the nested PCR with oligonucleotides P204 and P276; lanes c, DraI digestion of the RT-nPCR products, yielding fragments of 142 and $35 \mathrm{bp}$; lanes $\mathrm{M}$, markers (sizes are given in base pairs on the left).

directly with the plasma detected FCoV RNA at 4, 10, and 15 days p.i.

To improve the sensitivity of the RT-nPCR assay, the viral RNA was extracted from the plasma by using a simple guanidinium thiocynate-silica concentration step (6). With this procedure, FCoV RNAs could be detected from the day 4 p.i. onwards. In one cat, FCoV RNA was detected already from the day 2 p.i. onwards. To measure the minimal amount of virus that can be detected by silica extraction and RT-PCR, 10-fold serial dilutions of tissue culture-grown FIPV strain 79-1146 were prepared with plasma from a specific-pathogenfree cat. Virus quantities as low as $10^{-1}$ and $10^{-3} 50 \%$ tissue culture infective dose units were reproducibly detected with the first and nested PCRs, respectively.

To explore the diagnostic potential of RT-PCR, in a doubleblind study we analyzed serum, plasma, or ascitic fluid samples from 26 cats suspected of having FIP. For 18 cats, a definite diagnosis of FIP was established by postmortem pathologic examination; for the remaining 8 cats, a disease other than FIP was diagnosed (Table 3$)$. Of the 18 cats with FIP, $9(50 \%)$ were positive for FCoV in the RT-nPCR assay with serum. Five additional cats were positive upon analysis of plasma or ascitic fluid. Thus, FCoV RNA was detected in 14 of 18 cats with FIP (78\%). FCoV RNA was also detected in the serum of a cat diagnosed with feline leukemia. No FCoV RNA was detected in the sera of the other cats that had conditions other than FIP. 
TABLE 3. Comparison of RT-nPCR, serology, and pathology in cats with suspected FIP

\begin{tabular}{lccrrl}
\hline & \multicolumn{3}{c}{ RT-nPCR result for: } & & \\
Cat & IFA titer & \\
& Serum & Plasma & Ascites $^{b}$ & & \\
\hline A22 & + & & & $>2,560$ & FIP \\
A13 & - & + & + & 1,280 & FIP \\
A18 & - & & & 1,280 & FIP \\
A09 & + & & & 320 & FIP \\
A17 & + & + & & 320 & FIP \\
A19 & - & & & 320 & FIP \\
A02 & - & & + & 320 & FIP \\
A16 & & - & + & 320 & FIP \\
A24 & + & & & 160 & FIP \\
A01 & + & & & 80 & FIP \\
A11 & + & & & 80 & FIP \\
A25 & + & & & 80 & FIP \\
A15 & + & + & & 40 & FIP \\
A10 & - & & + & 40 & FIP \\
A23 & - & & & 40 & FIP \\
A05 & + & & & 20 & FIP \\
A26 & - & & & $<20$ & FIP \\
A21 & & & + & ND & FIP \\
A03 & - & & & 80 & No FIP \\
A08 & - & & & 20 & No FIP \\
A14 & - & - & & 20 & No FIP \\
A06 & - & & & $<20$ & No FIP \\
A07 & - & & & $<20$ & No FIP \\
A12 & - & & & $<20$ & No FIP \\
A20 & - & & & $<20$ & No FIP \\
A04 & + & & - & $<20$ & No FIP \\
\hline & & & & & \\
\hline
\end{tabular}

${ }^{a}$ IFA, immunofluorescence assay. For all cats except A16, titers are those in serum. For cat A16, the titer is that in plasma.

${ }^{b}$ Fluid from thorax or abdominal cavity.

${ }^{c} \mathrm{ND}$, not determined.

${ }^{d}$ The cat was not histopathologically examined. The diagnosis of no FIP was based on the overall clinical signs.

The anti-FCoV antibody titers in the serum and plasma samples were determined by immunofluorescence. Of the 18 cats determined by histopathology to have FIP, only 8 cats had titers of $\geq 320$ (Table 3 ).

Detection of FCoV RNA in fecal and plasma samples of asymptomatic cats. To determine whether RT-PCR can be used to identify shedders of FCoV, we studied seven Norwegian Forest cats from a cattery. The majority of these cats were FCoV seropositive. They had occasional diarrhea but were apparently healthy, and there were no cases of FIP in the cattery. Fecal samples were collected from seven cats of different ages at three different times over an 8-month period (Table 4). All samples were normal stools. Fecal suspensions in PBS were subjected to RT-nPCR either directly or, to increase sensitivity, after guanidinium thiocyanate- $\mathrm{SiO}_{2}$ extraction. As shown in Table 4, all cats shed FCoV at one of the collection times. FCoV RNA was detected in the feces of cats 1,2 , and 7 at all three sampling dates, suggesting chronic virus shedding. Surprisingly, FCoV RNA was also found in the plasma samples from two of the cats (cats 1 and 5).

\section{DISCUSSION}

We have developed an RT-nPCR assay for the detection of coronavirus RNA in plasma, tissue, and feces of infected cats. The assay is targeted to the $3^{\prime}$-UTR of the viral genome. Because the nucleotide sequence of this region is highly conserved among CCV, TGEV, and the various FCoV isolates (11, 17, 20, 43), the RT-nPCR should detect most, if not all,
TABLE 4. Detection of FCoV RNA in feces and plasma samples from asymptomatic cats

\begin{tabular}{|c|c|c|c|c|c|c|c|c|c|}
\hline \multirow{4}{*}{ Cat } & \multirow{4}{*}{$\operatorname{Age}^{a}$} & \multicolumn{7}{|c|}{ RT-nPCR with: } & \multirow{4}{*}{$\begin{array}{l}\text { IFA titer } \\
\text { in serum }^{b}\end{array}$} \\
\hline & & \multicolumn{6}{|c|}{ Feces $^{c}$} & \multirow{3}{*}{ Plasma $^{d}$} & \\
\hline & & \multicolumn{2}{|c|}{ March } & \multicolumn{2}{|c|}{$\begin{array}{l}\text { May- } \\
\text { June }\end{array}$} & \multicolumn{2}{|c|}{ November } & & \\
\hline & & $\mathrm{D}$ & E & $\mathrm{D}$ & E & $\mathrm{D}$ & $\mathrm{E}$ & & \\
\hline 1 & $1.5 \mathrm{yr}$ & + & & + & & - & + & + & 640 \\
\hline 2 & $7 \mathrm{mo}$ & + & & + & & + & & - & 160 \\
\hline 3 & $1.5 \mathrm{yr}$ & + & & & & - & + & - & 80 \\
\hline 4 & $6 \mathrm{mo}$ & & & - & + & + & & - & 80 \\
\hline 5 & $4.5 \mathrm{yr}$ & - & + & + & & + & & + & 40 \\
\hline 6 & $4 \mathrm{yr}$ & - & + & - & - & - & - & - & 40 \\
\hline 7 & $5 \mathrm{yr}$ & & & + & & - & - & - & $<20$ \\
\hline
\end{tabular}

${ }^{a}$ Age on the date of the first sampling.

${ }^{b}$ IFA, immunofluorescence assay. Samples were taken between 21 and 24 November.

${ }^{c}$ RT-nPCR was performed with fecal suspensions directly (D) or after $\mathrm{SiO}_{2}$ RNA extraction (E). Fecal samples were taken on 12 March, from 21 May to 2 June, and from 21 to 24 November. Open spaces indicate that samples were unavailable.

${ }^{d}$ Samples were taken between 21 and 24 November.

FCoV strains circulating in the cat population. The assay does not distinguish between virulent and avirulent FCoV strains, nor will it discriminate FCoV from TGEV and CCV. Although cats can be experimentally infected with CCV and TGEV (4, $22,42,46)$, it is not known whether these viruses infect cats naturally. The assay is highly sensitive: FCoV RNA was detected in the plasma of experimentally infected cats from as early as 2 to 4 days p.i.

To assess the diagnostic potential of RT-PCR, we analyzed serum, plasma, or ascitic fluid samples from 26 cats for which FIP had been considered a likely diagnosis. By histopathologic examination a definite diagnosis of FIP was established for 18 of these cats. Viral RNA was detected by RT-nPCR in 14 of the 18 cats with FIP (78\%). As shown in Table 3, in most cases only serum was available. A higher success rate may have been obtained if plasma had been used instead. Dilution experiments in which plasma and serum samples from the same cat were compared showed that RT-nPCR with plasma is 10 -fold more sensitive (15). However, even if it were possible to detect FCoV RNA in $100 \%$ of the cats with FIP, the use of RT-PCR for FIP diagnosis is limited because of the occurrence of FCoV carriers. Of the eight cats with diseases other than FIP, one cat diagnosed with feline leukemia was positive in the RT-nPCR. Moreover, of seven asymptomatic cats that shed FCoV in their feces, two had detectable virus in the plasma (Table 4). A larger survey of 41 asymptomatic cats from a breeding colony revealed that $73 \%$ of these cats shed $\mathrm{FCoV}$ in their stools, whereas for $37 \%$ of these cats, FCoV RNA was detected in the plasma (16). While it thus appears that RT-PCR with plasma or serum cannot be used to establish a definite diagnosis of FIP, the assay does provide a new means to identify asymptomatic FCoV carriers.

Thus far, only circumstantial evidence for the existence of an FCoV carrier state has been presented. Kittens exposed to asymptomatic seropositive cats seroconvert within 2 to 10 weeks; subsequently, some of them develop FIP $(1,2,35)$. Furthermore, FIP can be induced in healthy cats by immunosuppression: cats exposed to virulent FCoV and kept in isolation for up to 4 months developed FIP after an experimental superinfection with feline leukemia virus (32). The detection of FCoV in the feces of healthy seropositive cats, described in this 
paper, provides direct evidence for virus shedding by asymptomatic carriers. Of the cats listed in Table 4, three of seven shed virus in the feces at three consecutive times over a period of 8 months. Although these cats may have gone through periodic subclinical FCoV infections, they may instead have been persistently infected during the entire 8-month period. Whether the FCoV in these cats can induce FIP is unknown. Thus far, no cases of FIP in this cattery have been reported. Recently, however, one kitten developed FIP shortly after it had been sold.

Several questions about natural FCoV infections remain to be answered. What percentage of seropositive cats shed the virus? Does viral shedding occur continuously or periodically? If FCoVs cause a true persistent infection, which cells and/or tissues harbor the virus? This RT-nPCR assay will provide a powerful tool to address these issues. Moreover, the test will be important in the management of cat breeding colonies. Previous studies have shown that early weaning and isolation can prevent kittens from being infected with $\mathrm{FCoV}(1,2)$. In catteries where FCoV is present, the RT-nPCR may be of use in the identification of asymptomatic FCoV shedders. Perhaps more importantly, RT-nPCR allows screening of cats for FCoV infection before their introduction into FCoV-free cat breeding colonies.

\section{ACKNOWLEDGMENTS}

We thank Niels Pedersen, Dave Harbour, Katrin Hartmann, and Harry Vennema for generously providing virus stocks, cells, and clinical materials. We are indebted to Albert Osterhaus for providing virus stocks and the facility to carry out experimental infections of cats and to Alfred M. Legendre for most-valuable suggestions on the manuscript.

A. Herrewegh was supported by a research grant from Solvay Animal Health Inc., Mendota Heights, Minn. The research by R. J. de Groot was made possible by a fellowship from the Royal Netherlands Academy of Arts and Science.

\section{REFERENCES}

1. Addie, D. D., and J. O. Jarrett. 1992. A study of naturally occurring feline coronavirus infections in kittens. Vet. Rec. 130:133-137.

2. Addie, D. D., and J. O. Jarrett. 1992. Feline coronavirus antibodies in cats. Vet. Rec. 131:202-203.

3. Barlough, J. E. 1984. Serodiagnostic aids and management practice for feline retrovirus and coronavirus infections. Vet. Clin. N. Am. 14:955-969.

4. Barlough, J. E., C. A. Stoddart, G. P. Sorresso, R. H. Jacobson, and F. W. Scott. 1984. Experimental inoculation of cats with canine coronavirus and subsequent challenge with feline infectious peritonitis virus. Lab. Anim. Sci. 34:592-597.

5. Black, J. W. 1980. Recovery and in vitro cultivation of a coronavirus from laboratory-induced cases of feline infectious peritonitis (FIP). Vet. Med. Small Anim. Clin. 75:811-814.

6. Boom, R., C. J. A. Sol, M. M. M. Salimans, C. L. Jansen, P. M. E. Wertheimvan Dillen, and J. Van der Noordaa. 1990. A rapid and simple method for purification of nucleic acids. J. Clin. Microbiol. 28:495-503.

7. Boyle, J. F., N. C. Pedersen, J. F. Evermann, A. J. McKeirnan, R. L. Ott, and J. W. Black. 1984. Plaque assay, polypeptide composition and immunochemistry of feline infectious peritonitis virus and feline enteric coronavirus isolates. Adv. Exp. Med. Biol. 173:133-147.

8. Corapi, W. V. 1994. Personal communication.

9. Corapi, W. V., C. W. Olsen, and F. W. Scott. 1992. Monoclonal antibody analysis of neutralization and antibody-dependent enhancement of feline infectious peritonitis virus. J. Virol. 66:6695-6705.

10. De Groot, R. J., A. C. Andeweg, M. C. Horzinek, and W. J. M. Spaan. 1988. Sequence analysis of the $3^{\prime}$-end of the feline coronavirus FIPV 79-1146 genome: comparison with the genome of porcine coronavirus TGEV reveals large insertions. Virology 167:370-376.

11. De Groot, R. J., R. J. Ter Haar, M. C. Horzinek, and B. A. M. Van der Zeijst. 1987. Intracellular RNAs of the feline infectious peritonitis coronavirus strain 79-1146. J. Gen. Virol. 68:995-1002.

12. Evermann, J. F., L. Baumgartner, R. L. Ott, E. V. Davis, and A. J. McKeirnan. 1981. Characterization of a feline infectious peritonitis virus isolate.
Vet. Pathol. 18:256-265

13. Fiscus, S. A., and Y. A. Teramoto. 1987. Antigenic comparison of feline coronavirus isolates: evidence for markedly different peplomer glycoproteins. J. Virol. 61:2607-2613.

14. Goitsuka, R., Y. Hirota, A. Hasegawa, and I. Tomoda. 1987. Release of interleukin 1 from peritoneal exudate cells of cats with feline infectious peritonitis. Jpn. J. Vet. Sci. 49:811-818.

15. Herrewegh, A. A. P. M. Unpublished data

16. Herrewegh, A. A. P. M., M. Mähler, H. J. Hedrich, M. C. Horzinek, and R. J. de Groot. Unpublished data

17. Herrewegh, A. A. P. M., H. Vennema, M. C. Horzinek, P. J. M. Rottier, and R. J. de Groot. Unpublished data.

18. Hohdatsu, T., S. Okada, and H. Koyama. 1991. Characterization of monoclonal antibodies against feline infectious peritonitis virus type II and antigenic relationship between feline, porcine, and canine coronaviruses. Arch. Virol. 117:85-95.

19. Hohdatsu, T., T. Sasamoto, S. Okada, and H. Koyama. 1991. Antigenic analysis of feline coronaviruses with monoclonal antibodies (MAbs): preparation of MAbs which discriminate between FIPV strain 79-1146 and FECV strain 79-1683. Vet. Microbiol. 28:13-24.

20. Horsburgh, B. C., I. Brierley, and T. D. Brown. 1992. Analysis of a $9.6 \mathrm{~kb}$ sequence from the $3^{\prime}$ end of canine coronavirus genomic RNA. J. Gen. Virol. 73:2849-2862.

21. Loeffler, D. G., R. L. Ott, J. F. Evermann, and J. E. Alexander. 1978. The incidence of naturally occuring antibodies against feline infectious peritonitis in selected cat populations. Feline Pract. 8:43-47.

22. McArdle, F., M. Bennett, R. M. Gaskell, B. Tennant, D. F. Kelly, and C. J. Gaskell. 1992. Induction and enhancement of feline infectious peritonitis by canine coronavirus. Am. J. Vet. Res. 53:1500-1506.

23. McKeirnan, A. J., J. F. Evermann, A. Hargis, L. M. Miller, and R. L. Ott. 1981. Isolation of feline coronavirus from two cats with diverse disease manifestations. Feline Pract. 11:16-20.

24. Montali, R. J., and J. D. Strandberg. 1972. Extraperitoneal lesions in feline infectious peritonitis. Vet. Pathol. 9:109-121.

25. O'Reilly, K. J., L. M. Fishman, and L. M. Hitchcock. 1979. Feline infectious peritonitis: isolation of a coronavirus. Vet. Rec. 104:348.

26. Osterhaus, A. D. M. E., M. C. Horzinek, and R. M. S. Wirahadiredja. 1978. Feline infectious peritonitis (FIP) virus. II. Propagation in suckling mouse brain. Zentralbl. Vet. Med. B 25:301-307.

27. Pedersen, N. C. 1976 . Morphologic and physical characteristics of feline infectious peritonitis virus and its growth in autochtonous peritoneal cell cultures. Am. J. Vet. Res. 37:567-572.

28. Pedersen, N. C. 1976. Serologic studies of naturally occuring feline infectious peritonitis. Am. J. Vet. Res. 37:1449-1453

29. Pedersen, N. C. 1976. Feline infectious peritonitis: something old, something new. Feline Pract. 6:42-51.

30. Pedersen, N. C. 1983. Feline infectious peritonitis and feline enteric coronavirus infections. 1. Feline enteric coronaviruses. Feline Pract. 13(4):1319.

31. Pedersen, N. C. 1983 . Feline infectious peritonitis and feline enteric coronavirus infections. 2. Feline infectious peritonitis. Feline Pract. 13(5):520.

32. Pedersen, N. C. 1987. Virologic and immunologic aspects of feline infectious peritonitis virus infection. Adv. Exp. Med. Biol. 218:529-550.

33. Pedersen, N. C., J. W. Black, J. F. Boyle, J. F. Evermann, A. J. McKeirnan, and R. L. Ott. 1983. Pathogenic differences between various feline coronavirus isolates. Adv. Exp. Med. Biol. 173:365-380.

34. Pedersen, N. C., J. F. Boyle, and K. Floyd. 1981. Infection studies in kittens utilizing feline infectious peritonitis virus propagated in cell culture. Am. J. Vet. Res. 42:363-367.

35. Pedersen, N. C., J. F. Boyle, K. Floyd, A. Fudge, and J. Barker. 1981. An enteric coronavirus infection of cats and its relationship to feline infectious peritonitis. Am. J. Vet. Res. 42:368-377.

36. Pedersen, N. C., and K. Floyd. 1985. Experimental studies with three new strains of feline infectious peritonitis virus: FIPV-UCD2, FIPV-UCD3, and FIPV-UCD4. Compend. Contin. Educ. Pract. Vet. 7:1001-1011.

37. Smith, D. B., and K. S. Johnson. 1988. Single-step purification of polypeptides expressed in Escherichia coli as fusions with glutathione S-transferase. Gene 67:31-40.

38. Sparkes, A. H. 1992. Feline coronavirus antibodies in UK cats. Vet. Rec. 131:223-224.

39. Sparkes, A. H., T. J. Gruffydd-Jones, and D. A. Harbour. 1991. Feline infectious peritonitis: a review of clinicopathological changes in 65 cases, and a critical assessment of their diagnostic value. Vet. Rec. 129:209-212.

40. Sparkes, A. H., T. J. Gruffydd-Jones, P. E. Howard, and D. A. Harbour. 1992. Coronavirus serology in healthy pedigree cats. Vet. Rec. 131:35-36.

41. Stoddart, C. A., and F. W. Scott. 1989. Intrinsic resistance of feline peritoneal macrophages to coronavirus infection correlates with in vivo virulence. J. Virol. 63:436-440.

42. Toma, B., C. Duret, G. Chappuis, and B. Pellerin, 1979. Echec de l'immunisation contre la peritonite infectieuse feline par injection de virus de la gastro-enterite transmissible du porc. Rec. Med. Vet. 155:799-803. 
43. Vennema, H., J. W. Rossen, J. Wesseling, M. C. Horzinek, and P. J. Rottier. 1992. Genomic organization and expression of the $3^{\prime}$ end of the canine and feline enteric coronaviruses. Virology 191:134-140.

44. Ward, J. M. 1970. Morphogenesis of a virus in cats with experimental feline infectious peritonitis. Virology 41:191-194.

45. Weiss, R. C., and F. W. Scott. 1981. Pathogenesis of feline infectious peritonitis: nature and development of viremia. Am. J. Vet. Res. 42:382390.

46. Witte, K. H., K. Tuch, H. Dubenkropp, and C. Walther. 1977. Untersuchungen uber die Antigenverwandschaft der Viren der Felinen Infectiosen Peritonitis und der transmissibelen Gastroenteritis des Schweines. Berl. Munch. Tierarztl. Wschr. 90:396-401. 